플 Science Press Springer-Verlag

\title{
Erratum to: Endophytic bacteria associated with endangered plant Ferula sinkiangensis K. M. Shen in an arid land: diversity and plant growth-promoting traits
}

LIU Yonghong ${ }^{1,2}$, GUO Jianwei ${ }^{1,3}$, LI Li $^{1}$, Mipeshwaree D ASEM ${ }^{4}$, ZHANG Yongguang ${ }^{1}$, Osama A MOHAMAD ${ }^{1,5}$, Nimaichand SALAM ${ }^{4}$, LI Wenjun ${ }^{1,4^{*}}$

${ }^{1}$ Key Laboratory of Biogeography and Bioresource in Arid Land, Xinjiang Institute of Ecology and Geography, Chinese Academy of Sciences, Urumqi 830011, China;

${ }^{2}$ University of Chinese Academy of Sciences, Beijing 100049, China;

${ }^{3}$ Key Laboratory of Crops with High Quality and Efficient Cultivation and Security Control, Yunnan Higher Education Institutions, Honghe University, Mengzi 661100, China;

${ }^{4}$ State Key Laboratory of Biocontrol and Guangdong Provincial Key Laboratory of Plant Resources, School of Life Sciences, Sun Yat-Sen University, Guangzhou 510275, China;

${ }^{5}$ Environmental Science Department, Institute for Post Graduate of Environment Study, Arish University, Arish 45511, Egypt

(C) Xinjiang Institute of Ecology and Geography, Chinese Academy of Sciences, Science Press and Springer-Verlag Berlin Heidelberg 2017

Erratum to: J Arid Land (2017) 9(3): 432-445

doi: $10.1007 / \mathbf{s} 40333-017-0015-5$

In this Erratum, we need to specifically point out that the first author and the seventh author contributed equally to the paper.

The online version of the original article can be found under doi: 10.1007/s40333-017-0015-5.

*Corresponding author: Li Wenjun (E-mail: liwenjun3@mail.sysu.edu.cn) 